Résumés des conférences et travaux

Les représentations de l'espace en Occident de l'Antiquité tardive au $\mathrm{XVI} I^{e}$ siècle

\title{
Cartographie et culture princière en France au XVI siècle
}

\section{Margriet Hoogvliet}

\section{OpenEdition}

\section{Journals}

Édition électronique

URL : https://journals.openedition.org/ashp/361

DOI : 10.4000/ashp.361

ISSN : 1969-6310

\section{Éditeur}

Publications de l'École Pratique des Hautes Études

Édition imprimée

Date de publication : 1 octobre 2008

Pagination : 124-128

ISSN : 0766-0677

Référence électronique

Margriet Hoogvliet, «Cartographie et culture princière en France au xvle siècle », Annuaire de l'École pratique des hautes études (EPHE), Section des sciences historiques et philologiques [En ligne], 139 | 2008, mis en ligne le 05 janvier 2009, consulté le 12 juillet 2021. URL : http://journals.openedition.org/ashp/ 361 ; DOl : https://doi.org/10.4000/ashp.361 


\title{
CARTOGRAPHIE ET CULTURE PRINCIÈRE EN FRANCE AU XVI ${ }^{e}$ SIÈCLE
}

\author{
Conférences de $\mathrm{M}^{\mathrm{me}}$ Margriet Hoogvliet, \\ département des langue et culture françaises, \\ université d'Utrecht, \\ maître de conférences invité
}

\section{Cartographie et pouvoir}

Loin d'être des notations neutres des contours de la terre, les cartes doivent être considérées comme un discours traduisant des idéologies politiques et, par conséquent, comme un instrument du pouvoir, comme un moyen de sa légitimation et parfois comme une prise de possession symbolique.

À partir du début du $\mathrm{XVI}^{\mathrm{e}}$ siècle les monarques européens se sont intéressés à l'établissement de documents cartographiques de leurs territoires. Les rois de France pouvaient seulement avoir recours aux cartes marines et aux cartes de la Gaule antique dans les éditions de la Géographie de Ptolémée. La première carte moderne et indépendante de la France est celle établie par Oronce Fine, intitulée Nova totius Galliae descriptio et imprimée à partir de 1525. Pour disposer d'une description plus détaillée du territoire, la régente Catherine de Médicis commanda vers 1560 à Nicolas de Nicolay une entreprise cartographique encore plus systématique : « La visitation et description générale et particulière du royaulme ». Sans doute à cause des troubles des guerres de Religion, seuls trois volumes furent complétés : les descriptions du Berry et du diocèse de Bourges (1567), du Bourbonnais (1569) et du Lyonnais et du Beaujolais (1573). Il s'agit de descriptions encyclopédiques et exhaustives, munies de cartes détaillées. Cependant, la mise en carte n'est pas de façon univoque une affaire du pouvoir politique qui cherche à soumettre ses sujets. Ainsi, en décrivant le diocèse de Bourges, Nicolay insiste sur les franchises et les privilèges des habitants de la ville.

Les cartes ont aussi joué un rôle important dans la culture princière du $\mathrm{XVI}^{\mathrm{e}}$ siècle. Par la possession de cartes évoquant des pays lointains de l'Orient et du Nouveau Monde, les rois cherchèrent en effet à légitimer leurs droits sur ces territoires. Certaines prophéties apocalyptiques jouèrent aussi un rôle. Plusieurs textes annoncent la venue d'un monarque depuis l'Occident préalable à la venue de l'Antéchrist et au Jugement Dernier. Un souverain qui s'affichait avec un globe ou une carte du monde pouvait ainsi être considéré comme ce dernier monarque destiné à soumettre le monde entier.

\section{Les cartes dans la collection de Catherine de Médicis}

Un inventaire des biens meubles de l'hôtel de Catherine de Médicis fut dressé après sa mort en 1589. Dans une des salles de l'hôtel, « le quatrième galetas cabinet de ladicte feue dame », l'inventaire mentionne une grande quantité d'objets, appa- 
remment rassemblés de façon incohérente. Cependant, on reconnaît ces objets comme des représentants des naturalia, des artificialia, des antiquitates et des orientalia. La grande quantité de poupées et d'objets en miniature s'explique de même par rapport à la culture des collections.

Les cartes géographiques forment un autre aspect. L'inventaire mentionne « une carte universelle de Postel avec son chassis doré », ainsi qu'un atlas de cartes nautiques et les trois volumes manuscrits de Nicolay sur le Berry, le Bourbonnais et Lyon. Dans une autre salle se trouvait encore une collection d'une trentaine de cartes. Leur présence peut s'expliquer par le désir de visualiser la provenance de la collection et de l'ordonner de façon géographique, comme l'avait projeté le gendre de Catherine, Côme de Médicis, dans ce qu'on appelle de nous jours la « Sala delle mappe geografiche » du Palazzo Vecchio à Florence.

Les collections princières fonctionnaient aussi comme representatio idéologique du prince : une collection coûteuse qui englobait des objets représentant le macrocosme était une manifestation tangible de la puissance et de la grandeur du propriétaire. La présence de la carte de Guillaume Postel (ce dernier avait prophétisé, entre autres dans ses Raisons de la Monarchie de 1551 qu'un roi de France serait le dernier monarque), ainsi qu'un volume contenant les prophéties sibyllines (où la venue du dernier monarque est annoncée) suggèrent qu'il s'agit d'un programme idéologique et politique où Catherine de Médicis a cherché à démontrer le destin grandiose des ses fils, dont trois furent roi de France. Ceci n'était pas sans précédent au XVI ${ }^{\mathrm{e}}$ siècle : la collection rassemblée dans son château de Malines par Marguerite d'Autriche, la régente des PaysBas espagnols, comprenait un grand nombre d'objets provenant du Nouveau Monde ainsi que des documents cartographiques. La collection de Malines était probablement destinée à démontrer la puissance et la grandeur de la famille de Habsbourg.

\section{Les globes dans les entrées royales}

Les empereurs romains affichaient comme signe de leur pouvoir universel une sphère représentant l'univers, souvent surmontée d'une Victoire. Même s'il y a des exemples iconographiques plus anciens, l'empereur Henri II semble avoir été le premier souverain médiéval recevant lors de son couronnement (1014) un Reichsapfel. Cette « pomme » vraisemblablement surmontée d'une croix était symbole de l'empire, mais elle dotait aussi le porteur de connotations christologiques tout en exprimant les prétentions à la domination universelle. Au Moyen Âge, le Reichsapfel représentait l'univers, c'est-à-dire l'ensemble de la terre et des cieux (mundus). Parfois l'univers se confond avec l'orbis terrarum et il y a en effet quelques exemples où l'on a gravé sur le globe des tracés géographiques de la terre, comme, par exemple, un relief en ivoire datant $\mathrm{du} \mathrm{XIII}^{\mathrm{e}}$ siècle où l'on voit un roi avec un objet sphérique portant les noms des trois parties du monde habité.

En 1494 Alphonse II et en 1495 le roi français Charles VIII, lors de leurs entrées solennelles à Naples, portèrent dans leur main une " pomme en or ». Au début du XV siècle déjà des globes apparurent dans la culture festive des cours italiennes, mais il est douteux qu'il s'agisse toujours de globes terrestres. Le premier exemple serait l'entrée solennelle d'Alphonse à Naples en 1443, où il y eut de nombreuses référen- 
ces aux empereurs romains, parmi lesquelles un char avec César debout sur un globe tournant : " sub cuius pedibus mundus in formam sphaericam continue movebatur ». Cependant, comme le texte latin décrivant l'événement a recours au terme «mundus ", ce qui renvoie à l'ensemble de l'univers, il est peu probable qu'il s'agisse ici d'un globe terrestre.

La plupart des globes qui figurent dans la culture festive au $\mathrm{XV}^{\mathrm{e}}$ siècle sont probablement des globes célestes. En revanche, des globes terrestres paraissent régulièrement à partir du XVI ${ }^{\mathrm{e}}$ siècle pendant les fêtes à la cour et lors des entrées royales, surtout celles de la maison de Habsbourg. Pendant l'entrée solennelle de Charles Quint à Florence en 1536, il y eut une représentation de Prudence et de Justice avec un globe terrestre et l'aigle impérial. Lors de l'entrée de Philippe II à Anvers en 1549, la ville lui présenta des statues de Charles Quint et de lui-même portant un globe terrestre.

Même si traditionnellement les rois de France ne s'associent pas avec le Reichsapfel, des représentations des Valois comportant un globe terrestre apparaissent au XVI ${ }^{\mathrm{e}}$ siècle, manifestation de leurs aspirations politiques. Sur une médaille datant de 1515, François I ${ }^{\text {er }}$ est flanqué par deux globes avec le texte « Unus non sufficit orbis ». Sur la peinture de Raphaël du couronnement de Charlemagne (1515-17) au Vatican, on voit l'empereur - dépeint avec les traits de François $\mathrm{I}^{\mathrm{er}}$ - portant un globe terrestre dans sa main.

Les premiers globes terrestres dans des entrées royales apparurent pendant le règne de Henri II. Pour son entrée solennelle à Lyon en 1548, les poètes et les artistes avaient intégré plusieurs globes dans les décorations. Une statue de femme debout sur une roue faisant partie d'un ensemble appelé « L'occasion du Grand Palais » offrait au roi un « Globe terrestre geographiqement pourtraict en sa dimention ». L'inscription à ses pieds soulignait encore une fois les prétentions territoriales du roi : « Imperium sine fine dedi $»$.

Vers le milieu du XVI ${ }^{\mathrm{e}}$ siècle, le jeune roi Charles IX fut considéré comme le dernier monarque devant établir une paix durable qui durerait mille ans. Pendant les fêtes de Fontainebleau en 1564, son frère le duc d'Orléans lui fit offrir un globe terrestre en or par la déesse Junon. Lors de l'entrée de Charles IX et de la reine Elisabeth d'Autriche à Paris en 1571, un globe terrestre faisait partie des décorations de l'entrée du roi, mais pendant l'entrée de la reine le lendemain, on pouvait voir sur la porte du pont NotreDame une statue représentant Jupiter sous forme de taureau nageant avec la nymphe Asie sur le dos. Le commentaire du livret ajoutait que « le Daulphin de France qui doit sortir de ce mariage ravira l'Asie et le reste du monde pour joindre à son empire et soy faire Monarque de l'univers ».

Au Moyen Âge, le Reichsapfel n'était pas strictement réservé aux hommes. Au XVI ${ }^{\mathrm{e}}$ siècle, Élisabeth d'Angleterre fut souvent représentée avec un globe terrestre ou une carte géographique. La reine mère et régente Catherine de Médicis portait probablement un intérêt particulier à la géographie et c'est peut-être la raison pour laquelle on la représenta pendant l'entrée de Charles IX à Paris en 1571 tenant une carte de la Gaule.

\section{La France dans la Cosmographie universelle (1575) de François de Belleforest}

L'entreprise éditoriale de la Cosmographie universelle de tout le monde écrite par François de Belleforest et publiée en 1575 par Nicolas Chesneau et Michel Sonnius 
paraît très audacieuse. L'ouvrage en trois volumes contient plus de quatre mille pages et plusieurs cartes, ce qui demanda des investissements considérables pour la production et le stockage des cahiers déjà imprimés. Il n'est donc pas étonnant de voir les deux imprimeurs parisiens mener une campagne publicitaire, tant en France qu'à la foire de Francfort.

L'ouvrage de Belleforest est une adaptation de la Cosmographia. Beschreibung aller lender de Sébastien Münster publiée pour la première fois à Bâle en 1544. Comme Münster s'était occupé surtout de l'Allemagne, il fallait réécrire les chapitres sur la France afin de rendre l'ouvrage plus intéressant pour un public français. Belleforest avait envoyé aux élites locales des villes importantes du pays une demande de renseignements sur l'histoire et la géographie régionales. En bon philologue, il se fondait surtout sur des autorités textuelles reconnues, ce qui l'opposait à André Thevet, voyageur et cosmographe du roi en titre, auteur d'une autre Cosmographie universelle (1575). Dans la polémique véhémente entre les deux auteurs, Thévet dit de Belleforest qu'il « ne voyagea jamais nomplus [attaché ?] que les Hiboux qui repairent en l'Aqueduct d'Athenes, ou à l'Hippodrome Byzantin ». Belleforest répliqua aux accusations en posant qu'un seul homme ne pouvait jamais visiter toutes les régions de la terre et qu'un voyageur pouvait mentir facilement, faute de possibilités de vérifier la véracité de son récit.

Il semble qu'à l'origine Belleforest eût eu l'intention de dédier son ouvrage au roi Charles IX, mais comme ce dernier mourut en 1574, une année avant la publication, il fallait trouver un autre candidat. L'ouvrage est dédié « A tresillustre, et tres genereux prince Charles monseigneur, prothenotaire de la maison de Bourbon ». Il s'agit probablement de Charles III de Bourbon (1555-1607), fils illégitime d'Antoine de Bourbon et demi-frère du futur Henri IV. Charles de Bourbon s'était officiellement converti au catholicisme et plus tard il fut proclamé roi de France sous le nom de Charles X par les Ligueurs. Mais le texte de la Cosmographie universelle contient également des indices que l'auteur aurait eu l'intention de la dédier à un membre de la maison de Lorraine, celle des de Guise, les dirigeants du parti catholique.

Les descriptions géographiques de la Cosmographie universelle prennent souvent position dans les grands conflits politiques et religieux qui déchirèrent la France au $\mathrm{XVI}^{\mathrm{e}}$ siècle, car l'auteur s'en prend fréquemment aux calvinistes. Mais le texte ne vise pas uniquement le roi ou les candidats à la couronne française. Comme il s'agit d'une entreprise commerciale qui devait au moins rembourser les investissements, il était sans aucun doute nécessaire que la Cosmographie universelle intéressât un public assez vaste. Au début de la description de la France l'auteur fait remarquer que la Gaule telle qu'on la trouve dans la Geographie de Ptolémée ne correspond plus à la réalité. Belleforest choisit donc la disposition des neuf Parlements de la France comme fil conducteur du récit géographique. La trame de la description correspond donc à l'organisation politique et juridique du pays - ce qui montre que Belleforest et ses éditeurs visaient un public proche des Parlements, donc la noblesse de robe et les élites locales. Ceci s'accorde aussi avec la prise de position contre les calvinistes, car les cercles des parlementaires se rangeaient surtout dans le camp opposé.

La Cosmographie universelle ne traduit donc pas uniquement les intérêts du roi, mais son discours politique donne aussi place aux intérêts d'autres parties. Ainsi la 
cartographie politique n'apparaît pas comme un monologue, mais plutôt comme un dialogue. Un autre exemple se trouve dans la description de la ville de Saint-Denis. Tout comme l'ouvrage de Nicolay, le texte de la Cosmographie universelle souligne les droits des citoyens. La Cosmographie universelle est une œuvre géographique et en même temps la description géographique est une prise de position politique. Mais la perspective n'est pas univoque : le texte s'exprime contre les calvinistes, en faveur d'une royauté française catholique, tout en tenant compte des intérêts de la noblesse de robe, et aussi (des couches supérieures) du tiers état dans les parlements. La cartographie est un discours politique, mais il serait trop restrictif de considérer ce discours uniquement comme un moyen de surveillance et de soumission. 